\title{
Effect of EGR1-Mediated LncRNA HOTAIR on MRP1 Gene Expression and MDR in Lung Cancer
}

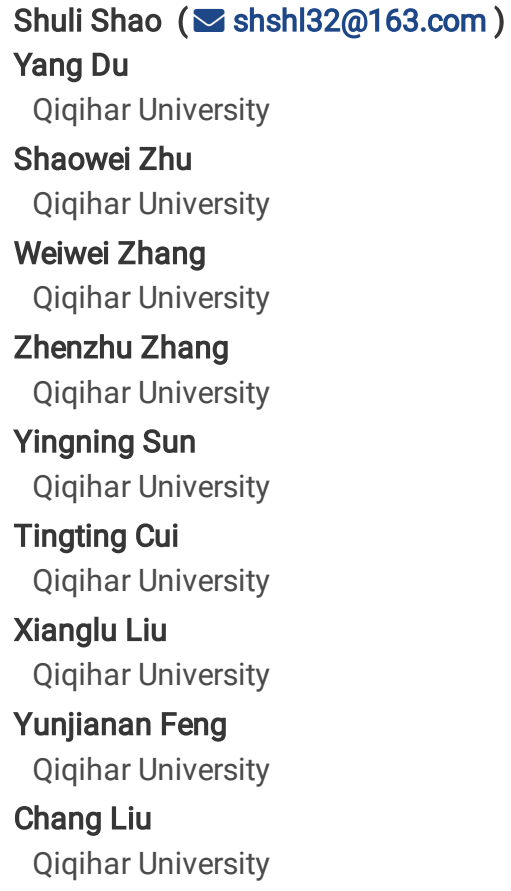

\section{Research}

Keywords: MRP1, EGR1, MDR, IncRNA HOTAIR

Posted Date: August 6th, 2020

DOI: https://doi.org/10.21203/rs.3.rs-52586/v1

License: (c) (i) This work is licensed under a Creative Commons Attribution 4.0 International License. Read Full License 


\section{Abstract}

Background: Multi-drug resistance-associated protein 1 (MRP1) plays critical roles in the multi-drug resistance (MDR) of cancer cells, and its expression is regulated by several transcription factors. However, the effects of EGR1 on MRP1 expression and MDR in lung cancer cells remain unknown.

Methods: The expression of Transcription factors EGR1 and IncRNA HOTAIR in Non-small cell lung cancer were detected by using qRT-PCR, at the same time, Western Blot was used to detect the expression of transcription factor EGR1. MTT assay, Flow Cytometry and Observation with laser confocal microscope assay were used to explore the role of EGR1 and IncRNA HOTAIR in Non-small cell lung cancer cells. ChIP PCR assay and Luciferase reporter assays were used to demonstrate the molecular biological mechanism of EGR1 and IncRNA HOTAIR in Nonsmall cell lung cancer.

Results: We found that EGR1 could bind to the MRP1 promoter at site -53/-42 bp and thereby regulate MRP1 expression. EGR1 knock-down reduced MRP1 expression, while EGR1 overexpression increased it. Knockdown of EGR1 increased the drug sensitivity to 5-Fluorouracil (5-FU), Toosendanin (TSN), and cisplatin (DDP), reduced the efflux ability of Rho-123, and induced apoptosis of drug-resistant lung cancer cells A549/DDP, while EGR1 overexpression had the opposite effects. Further, we demonstrated that IncRNA HOTAIR mediated the effects of EGR1 on MRP1 and MDR via sponging of miR-6807-3p. Moreover, we showed that miR-6807-3p exerts its function by targeting the EGR1 3'UTR.

Conclusions: We revealed the role and molecular mechanisms of the novel HOTAIR/miR-6807-3p/EGR1 axis in the regulation of MRP1 expression and MDR in lung cancer cells. Our findings identify EGR1 as a potential biomarker and therapeutic target for MDR in human lung cancer.

\section{Background}

Non-small-cell lung carcinoma has a high mortality and is currently treated mainly with chemotherapy. However, the development of multidrugresistance (MDR) to cytotoxic drugs during treatment interferes with the success of chemotherapeutic agents in most cases[1, 2]. The mechanisms that cancer cells utilize or develop to evade chemotherapy are complex[3-5], and include overexpression of multidrugresistance(MDR)-associated protein 1 (MRP1) as a major cause[6, 7]. MRPs belong to the superfamily of ATP-binding cassette transporters, a class of transmembrane proteins[8]. Overexpression of MRP1 induces a major drug-resistance phenotype or even MDR in cancer cells during chemotherapy by discharging anticancer drugs from cells, thus reducing their intracellular concentration[9-12]. Clinically, the expression of MRP1 is always increased in some cancers, such as nonsmall cell lung cancer (NSCLC)[13, 14], breast cancer, and prostate cancer[15], and is also related to accelerated relapse in breast cancer[16]. However, the mechanisms underlying the upregulation of MRP1 expression during chemotherapy remain largely unknown.

Early growth response 1 (EGR1, also known as NGFI-A, ZIF268, Krox24, or TIS8) is an immediate-early response gene and belongs to a family of zinc-finger transcription factors $[17,18]$. EGR1 can act as either an activator or a repressor of transcription through mechanisms that depend on interactions with, or regulation of, distinct cofactors[19], and has various functions in numerous contexts, including regulation of differentiation, growth, and apoptosis[20]. Previous studies have shown that EGR1 is closely related to the occurrence and development of tumors. EGR1 binds to the promoter of MDR1 and plays a key role in the regulation of the MDR1 gene[21]. However, the role of EGR1 in MRP1 expression and MDR development are still elusive.

Long non-coding RNAs (IncRNAs) were once considered to have no biological functions but are now regarded as important regulators. Accumulating evidence has shown that IncRNAs participate in epigenetic, transcriptional, and post-transcriptional gene regulation[22]. HOTAIR is the first antisense transcription IncRNA, which was found in human fibroblasts by Rinn et al[23]. Notably, IncRNA HOTAIR is closely related to MDR in gastric cancer and lung cancer[24, 25]. However, the mechanisms by which HOTAIR regulates MRP1 and MDR remain unclear.

The aim of this study was to elucidate the role of EGR1 and HOTAIR in regulation of MDR. We show that EGR1 can bind to the promoter region of the MRP1 gene and can be regulated by IncRNA HOTAIR through miR-6807-3p, thereby modulating the expression of MRP1 and affecting the MDR of human lung cancer.

\section{Materials And Methods}

\section{Cell culture}

Human lung cancer cell lines A549, A549/DDP, and human embryonic kidney cells HEK-293T were purchased from Shanghai Institute of Biosciences Cell Resource Center (Shanghai, China) and cultured in RPMI-1640 (Gibco Invitrogen, Carlsbad, CA, USA) supplemented with 10\% 
fetal bovine serum (FBS; Biological Industries Israel Bei-Haemek Ltd., Israel), $100 \mathrm{U} / \mathrm{mL}$ of penicillin sodium, and $100 \mu \mathrm{g} / \mathrm{mL}$ of streptomycin sulfate (Sangon Biotech Shanghai, China) at $37^{\circ} \mathrm{C}$ in a humidified atmosphere of 5\% $\mathrm{CO} 2$ (Thermo Electron, USA)[26].

\section{Construction of vectors}

\section{Construction of EGR1, IncRNA HOTAIR, and miR-6807-3p overexpression vectors}

The full-length EGR1 cDNA was amplified from A549/DDP total cDNA using PCR with primers containing the EcoRI/Hindlll restriction sites. The amplified product was purified and cloned into the pcDNA3.1 vector (Addgene, China) to generate the pcDNA3.1-EGR1 construct. The IncRNA HOTAIR sequence (NR: 003716.3) was searched according to the known HOTAIR gene sequence (GenelD: 100124700) in NCBI GenBank, and the full length IncRNA HOTAIR gene was chemically synthesized and then cloned into the pcDNA3.1 vector to construct pcDNA3.1-IncRNA HOTAIR. Full-length miR-6807-3p fragment was amplified by PCR from the total DNA of A549/DDP cells. The amplified product was purified and cloned into pcDNA3.1 vector to construct pcDNA3.1-miR-6807-3p. The empty pcDNA3.1 vector was used as a negative control. The primers used for plasmid construction are shown in Table 1.

\section{Construction of RNAi vectors}

Four short hairpin RNAs (shRNAs) targeting EGR1 were designed. The forward and reverse sequences were ligated to the circular loop sequence ( $5^{\prime}$-CGAA-3'), and the reverse sequence was ligated to the termination sequence (5'-TTTTTT-3') and the BamH I (Fermentas, China) restriction site at the $5^{\prime}$ end. At the $3^{\prime}$ end, there was an EcoRI (Fermentas, China) restriction site. The recombinant vectors were named shEGR11, shEGR1-2, shEGR1-3, and shEGR1-4. The pRNAT-H1.1/Shuttle-RFP (Scotch Plams, USA) empty plasmid was used as a control. To verify the specificity of the interfering fragment, the rescue vector pcDNA3.1-EGR1 ${ }^{\Delta}$ was constructed.

Three short hairpin RNAs (shRNAs) targeting IncRNA HOTAIR were designed. The forward and reverse sequences were ligated to the circular loop sequence (5'-CGAA-3'), and the reverse sequence was ligated to the termination sequence (5'-TTTTTT-3'), and the BamHI (Fermentas, China) restriction site at the $5^{\prime}$ end. At the $3^{\prime}$ end, there was a HindIII (Fermentas, China) restriction site. The recombinant vectors were named shLncRNA HOTAIR-1, shLncRNA HOTAIR-2, and shLncRNA HOTAIR-3. The pRNAT-H1.1/Shuttle-RFP (Scotch Plams, USA) empty plasmid was used as a control. To verify the specificity of the interfering fragment, the rescue vector pcDNA3.1-LncRNA HOTAIR ${ }^{\Delta}$ was constructed. The sequences of the shRNAs are shown in Table 2.

\section{Construction of luciferase reporter vectors}

For the MRP1 promoter reporter gene assay, the MRP1 gene promoter (-560 to $+176 \mathrm{bp}$ ) was PCR-amplified from A549/DDP genomic DNA and cloned into the pGL3-basal luciferase reporter plasmid (Promega, China) to generate pGL3-MRP1-600. Deletion mutagenesis of the predicted EGR1 binding site by nested PCR yielded pGL3-600- $\triangle E 1$ (AGGTGAGCGGGCGC), pGL3-600- $\triangle E 2$ (GGGGCGGGGGGG), pGL3-600- $\triangle E 3$ (TGGGGCGGGGC), and pGL3-600- $\triangle E 4$ mutant reporter genes; of these, pGL3-600- $\triangle E 4$ was simultaneously mutated at the three putative EGR1 binding sites.

For EGR1 3'UTR reporter assay, the entire 3' UTR of EGR1 was chemically synthesized and cloned into psiCHECK-2 dual-luciferase reporter plasmid. (Promega, Madison, WI, USA) immediately downstream of the stop codon of the luciferase gene to generate psiCHECK-2- EGR1 3' UTR-wt. The mutant EGR1 3'UTR reporter, designated as psiCHECK-2- EGR1 3' UTR-mut, was created by mutating the seed region of the predicted miR-6807-3p binding site (ATGCAGT to TACGTCA) through chemical synthesis.

The predicted interaction between IncRNA HOTAIR and miR-6807-3p was analyzed with the help of the DIANA tool on the biometric prediction website. Dual luciferase reporter assays were performed to determine if miR-6807-3p is a direct target of IncRNA HOTAIR. The binding region of IncRNA HOTAIR was cloned and chemically synthesized. The primers used for plasmid construction are shown in Table 3. All recombinant vectors were verified by sequencing after construction in Sangon Biotech Co., Ltd. (Shanghai, China).

\section{Real-time RT-PCR analysis}

Total RNA was extracted from A549 and A549/DDP cells using EZ-10 RNA Mini-Preps KitS (BIO BASIC INC, China). Total RNA was reverse transcribed to CDNA using Bioteke super RT Kit (Bioteke Corporation, China). The real-time PCR reactions were carried out in a 96-well microtiter plate using the power 2xSYBR Real-Time PCR Premixture kit (Bioteke Corporation, China) and Real-Time PCR (Eppendorf, USA). All samples were analyzed in triplicate in three independent experiments. The fluorescence of the PCR products was detected by the same apparatus. The number of cycles for the amplification plot to reach the threshold limit (Ct value) was used for quantification. $\beta$-actin and U6 were used as endogenous controls. Using the Ct values obtained by the analysis software, the relative expression levels of EGR1 and MRP1 mRNAs, IncRNA HOTAIR, and miR-6807-3p were calculated through the $2^{-\Delta \Delta C t}$ algorithm[26-28]. The primers used in PCR are shown in Table 4. 
The indicated cells were lysed in precooled lysis buffer (Western and IP Cell Lysate Kit from Beyotime Biotechnology, China) containing 150 $\mathrm{mM} \mathrm{NaCl}, 20 \mathrm{mM}$ Tris-Cl (pH 7.5), 1\% Triton X-100, and various inhibitors such as EDTA, sodium pyrophosphate, $\beta$-glycerophosphate, sodium orthovanadate, and leupeptin. The protein lysates were separated on $10 \%$ SDS-PAGE gels and electrophoretically transferred to polyvinylidene difluoride (PVDF) membranes (Merck Millipore, Germany). After antigen blocking, the membranes were incubated with primary antibodies (antimouse IgG Bioss) overnight at $4{ }^{\circ} \mathrm{C}$ with gentle shaking. Membranes were probed with the following primary antibodies: MRP1 (1:300, Bioss, China), EGR1 (1:300, Bioss, China), and GAPDH (internal control, 1:300, Bioss, China). The secondary rabbit anti-mouse IgG (LI-COR Biotechnology, USA) antibody was added subsequently at a 1:1000 dilution and incubated at $4{ }^{\circ} \mathrm{C}$ for 1 hour with gentle shaking[29]. Bands were visualized with the LI-COR OdysseyH scanner and software (LI-COR Biotechnology, USA). Blots (and gels) were imaged using an Odyssey Infrared Imaging System Scan resolution.

\section{Chromatin immunoprecipitation (ChIP)-PCR assay}

Based on the prediction, three putative EGR1-binding sites were found in MRP1 promoter, namely EGR1-1, AGGTGAGCGGGCGC (-68/-55 bp); EGR1-2, GGGGCGGGGCGG (-53/-42 bp); and EGR1-3, TGGGGCGGGGC (-39 -27 bp); where +1 is the transcription start site. To study the interaction between these putative binding sites and EGR1, ChIP-PCR assay was performed as described[30]. Briefly, the A549/DDP cells were grown to approximately 80\% confluence, treated with formaldehyde (Sigma, USA) for 10 minutes, and pulsed with ultrasonic waves on wet ice. Then, the samples were immunoprecipitated with control IgG (Bioss, China), anti-RNA polymerase II antibody, and anti-EGR1 antibody (Bioss, China). Afterwards, the protected DNA fragments were collected, and PCRs were performed using the following specific primer set: Forward Primer: GCCGAGAGGTGGCTGGTCC; Reverse Primer: CGCACCGCCGCCTGGTT. Finally, the products from PCRs were analyzed by $1.5 \%$ agarose gel electrophoresis.

\section{Luciferasereportergeneassay}

HEK-293T cells were grown in 24-well plates and co-transfected with $2 \mu \mathrm{L}$ polyethylenimine (PEI; Sigma), $0.5 \mu \mathrm{g}$ EGR1 overexpression vector, $0.5 \mu \mathrm{g}$ of MRP1 promoter-luciferase plasmid DNA, and $0.01 \mu \mathrm{g}$ of Renilla luciferase reporter plasmid DNA. After $4 \mathrm{~h}$ of incubation, the medium without fetal calf serum was replaced with 1640 complete medium. A549/DDP cells were grown in 24-well plates and co-transfected with $2 \mu \mathrm{L}$ PEI (Sigma), $0.5 \mu \mathrm{g} \mathrm{miR-6807-3p} \mathrm{overexpression} \mathrm{vector,} \mathrm{and} 0.5 \mu \mathrm{g}$ of HOTAIR luciferase plasmid DNA. After 4 hours of incubation, the serumfree medium was replaced with 1640 complete medium. Firefly and Renilla luciferase activities were measured 48 hours after transfection, using a dual-luciferase reporter system (Promega, WI, USA) following the manufacturer's protocol[27]. The firefly luciferase activity was normalized to the Renilla luciferase activity. Each experiment was repeated at least three times.

\section{Flow cytometry to determine the drug efflux of Rho-123}

Fluorescence intensity of Rho-123 (99\%, Shanghai Yuanyi Biotechnology Co., Ltd.) in A549/DDP transfected with the aforementioned expression vectors was detected using flow cytometry (BECKMAN COULTER, USA) to assess the change in MRP1 protein efflux capacity. The cells were collect in EP tubes containing $10 \mu \mathrm{g} / \mathrm{mL}$ Rho- 123 and incubated for 30 minutes at $37^{\circ} \mathrm{C}$ in a $5 \% \mathrm{CO}_{2}$ cell incubator. Flow cytometry was used to measure the fluorescence intensity and emission wavelength of Rho-123 in cells with excitation wavelengths of $488 \mathrm{~nm}$ and 530 $\mathrm{nm}[26]$. The subtraction of the fluorescence retained from the total fluorescence is the fluorescence index of Rho-123. This process was repeated three times and an average value was obtained to calculate the ability of Rho-123 to flow-out.

\section{Drug sensitivity evaluation via MTT assay}

In order to detect drug sensitivity, A549/DDP cells were exposed to cisplatin (DDP), Toosendanin (TSN), and 5-fluorouracil (5-FU). Thiazolyl blue tetrazolium bromide (MTT, Sangon Biotech shanghai, China) assay was used to detect changes in drug sensitivity and to measure halfinhibitory drug concentrations. A549/DDP cells were transfected with pRNAT-H1.1/Shuttle-RFP, pcDNA3.1, pRNAT-H1.1/Shuttle-RFP + pcDNA3.1, pRNAT-H1.1/Shuttle-RFP-shEGR1-3, or pcDNA3.1. The cells were cultured for $48 \mathrm{~h}$ with pcDNA3.1-Egr1 ${ }^{\Delta_{+}}$pRNAT-H1.1/Shuttle-RFPshEGR1-3 and seeded in 96-well plates at a density of $5 \times 10^{5}$ cells per well. After 48 hours of incubation, $20 \mu \mathrm{L} \mathrm{MTT}(5 \mathrm{mg} / \mathrm{mL})$ was added. After 5 hours of incubation, $180 \mu \mathrm{L}$ of DMSO was added to each well. After incubation at $37^{\circ} \mathrm{C}$ for 24 hours, the absorbance was measured at $570 \mathrm{~nm}$ using a microplate reader (TECAN, Switzerland) [26, 28].

\section{Observation of cell morphological changes}

According to the results of MTT assay, three anticancer drugs (DDP, TSN, and 5-FU) were added to A549/DDP cells transfected with different expression vectors. After 48 hours, acridine orange (AO) staining was performed. Cell morphology was observed under laser confocal microscope (Leica, Germany). 


\section{Statistical analysis}

All results are expressed as means \pm SD. Representative bands were selected from independent western blotting experiments. When data distributions approximated normality and two groups were compared, a Student's t-test was performed to evaluate the significance of differences. Differences were regarded as significant at a level of $\mathrm{P}<0.05$. All statistical tests were performed using Prism software (GraphPad).

\section{Results}

\section{EGR1 is overexpressed in multidrug-resistant lung cancer cells A459/DDP}

To uncover the role of EGR1 in the MDR of human lung cancer, its expression level was assessed in lung cancer cell lines A549 and multidrugresistant A549/DDP. qRT-PCR and western blot showed that the expression of EGR1 mRNA and protein was 3.15 and 1.92-fold higher, respectively, in A549/DDP cells than in A549 cells (Fig 1).

\section{EGR1 upregulates the expression of MRP1 gene in A549/DDP cells}

To investigate the role of EGR1 on the expression of MRP1 in A549/DDP cells, four interference vectors targeting EGR1 mRNA were transfected into A549/DDP cells for 24, 48, and 72 hours. The most efficient interference vector was sh-EGR1-3 in 48 hours, which decreased the expression of EGR1 mRNA and protein by 75\% and 62\%, respectively, and was thus chosen for use in the subsequent experiments (Fig 2A, 2B). The mRNA levels of MRP1 decreased significantly in EGR1 knock-down cells. By contrast, EGR1 and MRP1 mRNA levels increased by 7-fold and 2.6-fold, respectively, while protein levels increased by 2.13-fold and 1.87-fold at 48 hours, respectively, in EGR1-overexpressing cells. Rescue experiments, where sh-EGR1-3 and pcDNA3.1-EGR1 ${ }^{\Delta}$ were co-transfected into A549/DDP cells, showed that the expression of MRP1 gene was restored to a level consistent with that of the control group (Fig 2C, 2D). These results suggest that expression of EGR1 could positively regulate the expression of MRP1 gene.

\section{EGR1 knockdown reduces MDR and promotes apoptosis in A549/DDP cells}

Next, fluorescence intensity of Rho-123 was measured in A549/DDP cells transfected with sh-EGR1-3, pcDNA3.1-EGR1 ${ }^{\triangle}$, pcDNA3.1-EGR1, or control vectors for 48 hours to investigate the effect of EGR1 on efflux capacity of MRP1. The fluorescence intensity of Rho-123 was 2.23-fold higher in EGR1-silenced cells and 0.63 times lower in EGR1-overexpressing cells than in the control group, while there was no significant difference between the rescue experimental and control groups (Fig $3 \mathrm{~A}-\mathrm{H})$.

To detect the effect of EGR1 on the drug sensitivity and cell morphology of A549/DDP cells, the cells were transfected with sh-EGR1-3, pcDNA3.1-EGR1 ${ }^{\triangle}$, pcDNA3.1-EGR1, or control vectors for 48 hours, then treated with three anticancer drugs, 5-FU, TSN, and DDP. The IC50 values of these drugs in A549/DDP cells decreased significantly upon knock-down of EGR1 and increased significantly upon over-expression of EGR1, but there was no significant change in the rescue experimental group compared with the control group (Table 5). A549/DDP cells transfected with control vectors showed no significant difference in cell morphology and only the early stage of apoptotic body. Most EGR1 knock-down cells showed apoptosis and chromatin contraction, and some of the cells ruptured. Instead, EGR1-overexpressing cells showed no obvious sign of apoptosis and were relatively intact. The rescue experimental group had the same morphology as the control group and underwent early apoptosis (Fig 3I). These results indicate that silencing EGR1 gene expression can increase the sensitivity of cells to anticancer drugs DDP, TSN, and 5-FU, and promote apoptosis.

\section{EGR1 is a transcription factor of MRP1}

To explore the mechanisms by which EGR1 regulates the expression of MRP1 in A549/DDP cells, we analyzed the MRP1 promoter in search of putative EGR1 binding sites. The region between $-68 \mathrm{bp}$ and $-27 \mathrm{bp}$ (relative to the transcription start site) revealed four putative EGR1-binding sites through bioinformatic analysis (Fig 4A). ChIP-PCR was performed to detect whether EGR1 binds directly within the promoter region of MRP1. As shown in Figure 4B, EGR1 bound to the MRP1 promoter region at the putative binding sites, whereas the control IgG did not. Dual luciferase assays were then carried out to further confirm the specificity of EGR1 binding. A549/DDP cells were co-transfected with pGL3MRP1-600 (containing the promoter region of MRP1 from -560 to $+176 \mathrm{bp}$ ) or pGL3-600- $\Delta \mathrm{E} 1 \sim \Delta \mathrm{E} 4$ (the EGR1-binding site-mutated vectors) and pcDNA3.1-EGR1 and phRL-TK vector (known as control reporter vector). The results showed higher luciferase activity in cells transfected with pGL3-MRP1-600 than in those transfected with pGL3-basic. Instead, luciferase activity was lower in pGL3-600- $\triangle \mathrm{E} 1 \sim \triangle \mathrm{E} 4-\mathrm{transfected}$ than in pGL3-MRP1-600-transfected cells, but still higher than in pGL3-basic-transfected cells. The relative activity of luciferase in cells transfected with the deletion mutant pGL3-600- $\triangle \mathrm{E} 2$ was significantly reduced by approximately $98 \%$ (Fig $4 \mathrm{C}$ ). Taken together, these experiments show that EGR1 interacts with the MRP1 promoter region $-53 /-42 \mathrm{bp}$. 
Next, we explored the role of IncRNA HOTAIR in regulating MRP1 expression and MDR. First, we determined that the expression of HOTAIR was 1.81-fold higher in A549/DDP cells than in A549 cells (Fig S1). To investigate the relationship between HOTAIR and MRP1, we constructed HOTAIR overexpression plasmids and three HOTAIR-targeting shRNA-expressing plasmids. Of these, sh-LncRNA-H1 showed the highest knockdown efficiency (Fig 5A). As expected, MRP1 expression was greatly increased after HOTAIR overexpression and reduced after HOTAIR knockdown and was almost restored to the control level through rescue with an RNAi-resistant form of HOTAIR (Fig 5B). Interestingly, similar changes occurred in the expression of EGR1. Further, consistent with the direct regulation of MRP1 expression by HOTAIR, intracellular Rho-123 retention was dramatically decreased after HOTAIR overexpression, increased after HOTAIR knock-down, and fully restored after HOTAIR rescue (Fig 5C). These results reveal that IncRNA HOTAIR regulates MRP1 and contributes significantly to development of MDR and sensitivity of cells to chemotherapeutic drugs.

\section{EGR1 is critical for HOTAIR-mediated MRP1 upregulation and MDR}

To determine whether EGR1 is required for HOTAIR-mediated regulation of MRP1 expression and MDR, we tested the effect of EGR1 knockdown on MRP1 expression and MDR after overexpression of HOTAIR in A549/DDP cells. Expression of both HOTAIR and MRP1 showed a dramatic increase in cells transfected with pcDNA3.1-HOTAIR. Interestingly, the increased transcription and expression of MRP1 remained unaffected by the scrambled shRNA control but were abolished by EGR1 knock-down (Fig 6A, 6B). These results confirm the hypothesis that EGR1 expression and activity are critical for IncRNA HOTAIR to modulate MRP1 expression. In addition, retention of Rho-123, which was reduced by HOTAIR overexpression, was mostly restored by EGR1 knock-down (Fig 6C). These findings implicate that EGR1 is essential for HOTAIR to regulate MRP1 expression and MDR development.

\section{HOTAIR regulates the expression of EGR1 by sponging miR-6807-3p}

Next, we explored the mechanisms by which HOTAIR regulates the expression of EGR1. Using DIANA tools and Targetscan, we predicted that miR-6807-3p could bind to HOTAIR and EGR1 (Fig 7A). Dual luciferase assays were carried out to confirm the specificity of miR-6807-3p interaction with the putative binding sites. Compared to the cells transfected with control, cells co-transfected with pcDNA3.1-miR-6807-3p and psiCHECK2-HOTAIR-wt or psiCHECK2-EGR1-3'UTR-wt showed reduced luciferase activity (Fig 7B). Instead, the mutant plasmid had no effect. Upon overexpression of miR-6807-3p, EGR1 and MRP1 mRNA expression decreased by 53\% and 38\%, respectively, while protein expression decreased by $45 \%$ and $41 \%$, respectively. After treatment with a miR-6807-3p inhibitor, the mRNA expression of EGR1 and MRP1 increased by $36 \%$ and $33 \%$, respectively, and the protein level also increased by $78 \%$ and $44 \%$, respectively (Fig 7C, 7D). These findings indicate that miR6807-3p is crucial for regulation of EGR1 expression by IncRNA HOTAIR.

\section{Discussion}

Chemotherapy-based treatment is currently one of the most important approaches for several types of cancers but is hampered by the occurrence of MDR during the administration of chemotherapeutic agents. MRP1 upregulation is regarded as one of the main causes of MDR in cancer cells, but the mechanisms underlying this change in its expression remain obscure. EGR1 is an immediate-early gene that is induced by a wide variety of stimuli and has important roles in the responses of different types of cells[31-33]. EGR1 can promote both growth and apoptosis of tumor cells[34, 35]. In this study, we found that the expression of EGR1 in A549/DDP cells was higher than that in A549 cells (Fig. 1). Moreover, the expression of MRP1 and the efficiency of cell efflux in A549/DDP were increased upon EGR1 over-expression, and the opposite trend was observed upon EGR1 knock-down (Fig. 2, 3). These findings reveal that EGR1 may be involved in the regulation of MRP1 gene expression. As a nuclear transcription factor, EGR1 binds to a GC-rich motif (5'GCG/TGGGCG3') through its three zinc-finger DNA-binding domains[36] to modulate transcription of its target genes[19]. We identified putative EGR1 binding sites in the MRP1 upstream promoter sequence, and confirmed by ChIP analyses and dual luciferase assays that EGR1 could bind to a specific site that spans from nucleotides - 53 to -42 of the promoter (Fig. 4). So, we identified EGR1 as a transcription factor of MRP1 and demonstrated that it plays critical roles in MRP1 upregulation and MDR.

Recently, IncRNAs have been widely identified and annotated[37-39]. LncRNAs play important roles in a variety of cellular processes via modulating gene expression at different levels, including RNA transcription, editing, and transport, and protein translation[40-46]. Although increasing evidence highlights the important role of IncRNAs in human disease, reports about the role of IncRNAs in MDR at the molecular level are scarce. The HOTAIR gene is located on human chromosome 12, and the region between HOXC11 and HOXC12 in the HOXC cluster is composed of 6 exons[30]. In this study, we found that IncRNA HOTAIR was upregulated in A549/DDP cells (Fig S1), and overexpression of HOTAIR promoted MRP1 expression and MDR development. The opposite trend was observed when HOTAIR was silenced in A549/DDP cells. Importantly, the expression of EGR1 was upregulated after HOTAIR overexpression and downregulated after RNAi-based HOTAIR knock-down in A549/DDP cells (Fig. 5). Moreover, EGR1 knock-down substantially abolished MRP1 upregulation and MDR mediated by HOTAIR overexpression in A549/DDP cells (Fig. 6). Collectively, these data demonstrate that Egr1 mediates IncRNA HOTAIR regulation of MRP1 expression and plays a critical role in the development of MDR during chemotherapy. 
Recent studies demonstrated that IncRNAs regulate gene expression via several mechanisms[37, 47, 48]. Increasing evidence suggests that competing endogenous RNAs (ceRNAs) might be implicated in IncRNA-mediated target regulation[49-51]. The ceRNA hypothesis defines IncRNAs, pseudogenes, or mRNAs, as molecular sponges that can competitively bind to miRNAs and thereby modulate the activity and expression of their targets. Here, we used DIANA tools and Targetscan to predict the binding of HOTAIR and EGR1 to miR-6807-3p. Dual luciferase assays confirmed the specificity of this binding. Moreover, miR-6807-3p could regulate endogenous EGR1 expression (Fig. 7).

\section{Conclusion}

In summary, our study has revealed a new IncRNA HOTAIR/miR-6807-3p/EGR1 regulatory axis for MRP1 upregulation and defined EGR1 as a novel therapeutic target for the reversal of MDR and the efficient treatment of drug-resistant cancers.

\section{Abbreviations}

EGR1: Early growth response 1; MRP1: Multi-drug resistance-associated protein 1; MDR: multi-drug resistance; IncRNA HOTAIR: Long intergenic non-protein coding RNA HOTAIR; IncRNAs: Long non-coding RNAs; MTT: 3-(4,5-dimethyl-2-thiazolyl)-2,5-diphenyl-2-H-tetrazol ium bromide; shRNA: short hairpin RNA;

\section{Declarations}

\section{Acknowledgements}

Not applicable.

\section{Authors' contributions}

Yang Du performed data analysis and drafted the manuscript. ShaoWei Zhu, YingNing Sun, TingTing Cui, XiangLu Liu, YunJiaNan Feng, and Chang Liu performed data analysis and participated in intellectual discussion. WeiWei Zhang designed flow cytometry experiments and assisted with critical revisions of the manuscript. ZhenZhu Zhang designed and carried out the photography using confocal laser microscope. ShuLi Shao obtained funding for the study and assisted with the design and interpretation of the study, as well as critical revisions of the manuscript. All authors read and approved the final manuscript.

\section{Funding}

This work was supported by the National Natural Science Foundation of China (grant number: 31670843 and 31801148 ), the Natural Science Foundation of Heilongjiang Province, China (grant numbers: C2016057 and C201241), the Scientific Research Fund of Heilongjiang Provincial Education Department (grant numbers: 135109104 and 135209260), and the Basic scientific research Fund of Heilongjiang Provincial institutions of university (grant numbers: YSTSXK201809 and LTSW201737).

\section{Availability of data and materials}

All the data and materials supporting the conclusions were included in the main paper.

\section{Ethics approval and consent to participate}

Not applicable.

\section{Patient consent for publication}

Not applicable.

\section{Competing interests}

The authors declare that they have no competing interests.

\section{Author details}

${ }^{1}$ Department of Life Science and Agroforestry, Qiqihar University, 42 Wenhua Street, Qiqihaer 161006, Hei Longjiang Province, China. ${ }^{2}$ Key Laboratory of Resistance Gene Engineering and Protection of Biodiversity in Cold Areas, Qiqihar University, 42 Wenhua Street, Qiqihaer 161006, Hei Longjiang Province, China. 


\section{References}

1. Redmond KM, Wilson TR, Johnston PG, Longley DB. Resistance mechanisms to cancer chemotherapy. Front Biosci. 2008;13:5138-54. https://doi.org/10.2741/3070.

2. Zhang QC, Song YG, Cheng XS, Xu ZW, Matthew OA, Wang J, et al. Apatinib Reverses Paclitaxel-resistant Lung Cancer Cells (A549) Through Blocking the Function of ABCB1 Transporter. Anticancer Res. 2019;39(10):5461-71. https://doi.org/21873/anticanres.1 3739.

3. Gottesman MM. Mechanisms of cancer drug resistance. Annu Rev Med. 2002;53:615-27. https://doi.org/1146/annurev.med.53.082901.103929

4. Loe DW, Deeley RG, Cole SP. Characterization of vincristine transport by the M ( $r) 190000$ multidrug resistance protein (MRP): evidence for cotransport with reduced glutathione. Cancer Res. 1998;58:5130-6.

5. Gottesman MM, Fojo T, Bates SE. Multidrug resistance in cancer: role of ATP-dependent transporters. Nat Rev Cancer. 2002;2:48-58. https://doi.org/1038 /nrc7 06.

6. Cole S P C. Multidrug Resistance Protein 1 (MRP1, ABCC1), a "Multitasking” ATP-binding Cassette (ABC) Transporter. Journal of Biological Chemistry. 2014;289(45): 30880-8. http s://doi.org/1074/jbc.R114.609248.

7. Giaccone G, Ark-Otte J van, Rubio GJ, Gazdar AF, Broxterman HJ, Dingemans AM, et al. MRP is frequently expressed in human lung-cancer cell lines, in non-small-cell lung cancer and in normal lungs. Int J Cancer. 1996;66(6): 760-7. https://doi.org/1002/(SICI)1097-0 215(19960611)66:6<760::AID-IJC9 >3.0.C0;2-Y.

8. Sodani K, Patel A, Kathawala RJ, Chen ZS. Multidrug resistance associated proteins in multidrug resistance. Chinese Journal of Cancer. 2012;31(2): 58-72. https://doi.org/5732/ cjc.011.10329.

9. Gana CC, Hanssen KM, Yu DMT, Flemminga CL, Wheatleya MS, Conseilc G, et al. MRP1 modulators synergize with buthionine sulfoximine to exploit collateral sensitivity and selectively kill MRP1-expressing cancer cells. Biochem Pharmacol. 2019;168:237-48. htt ps://doi.org/10.1016/j.bcp.2019.07.009.

10. Shao SL, Zhang WW, Li XY, Zhang ZZ, Yun DZ, Fu B, et al. Reversal of MDR1 gene-dependent multidrug resistance in HL60/HT9 cells using short hairpin RNA expression vectors. Cancer Biotherapy \& Radiopharmaceuticals. 2010;25(2): 171-177. https://doi.org/10.1089/cbr.200 8.0611.

11. Conseil G, Deeley RG, Cole SPC. Polymorphisms of MRP1 (ABCC1) and related ATP-dependent drug transporters. Pharmacogenetics and Genomics. 2005;15(8):523-533. htt ps://doi.org/1097/01.fpc.0000167333.38528.ec.

12. Zhao J, Yu BY, Wang DY, Yang JE. Promoter polymorphism of MRP1 associated with reduced survival in hepatocellular carcinoma. World Journal of Gastroenterology. 2010; 16(48):6104. https://doi.org/3748/wjg.v16.i48.6104.

13. Wright SR, Boag AH, Valdimarsson G, Hipfner DR, Campling BG, Cole SPC, et al. Immunohistochemical detection of multidrug resistance protein in human lung cancer and normal lung. Clin Cancer Res. 1998;4:2279-2289. http://clincancerres.aacrjournals.org/conte $\mathrm{nt} / 4 / 9 / 2279$.

14. Filipits M, Suchomel RW, Dekan G, Haider K, Valdimarsson G, Depisch D, et al. MRP and MDR1 gene expression in primary breast carcinomas. Clin Cancer Res. 1996;2:1231-1237. https://doi.org/10.1016/0959-8049(96)84850-7.

15. Nagengast WB, Oude Munnink TH, Dijkers EC, Hospers GA, Brouwers AH, Schröder CP, et al. Multidrug resistance in oncology and beyond: from imaging of drug efflux pumps to cellular drug targets. Methods Mol Biol. 2010;596:15-31. https://doi.org/1007/978-1-607 61-4166_2.

16. Nooter K, de la Riviere GB, Klijn J, Stoter G, Foekens J. Multidrug resistance protein in recurrent breast cancer. Lancet. 1997;349:1885 1886. https://doi.org/1016/s0140-673 6(05)63876-7.

17. Karthikkeyan G, Nagaraj NR, Seeneevasan A, Natarajan SK, Vedantham S, Coral K. Hyperglycemia induced early growth response-1 regulates vascular dysfunction in human retinal endothelial cells. Microvascular Research. 2018;117:37. https://doi.org/1016/ j.mvr.2018.01.002.

18. Gashler A, Sukhatme VP. Early Growth Response Protein 1 (Egr-1): Prototype of a Zinc-finger Family of Transcription Factors. Progress in Nucleic Acid Research \& Molecular Biology. 1995;50(50):191-224. https://doi.org/1016/s0079-6603(08)60815-6.

19. Thiel G, Cibelli G. Regulation of life and death by the zinc finger transcription factor Egr-1. Journal of Cellular Physiology. 2002;193(3):287292. https://doi.org/1002/jcp.10178.

20. Pagel JI, Deindl E. Early growth response 1--a transcription factor in the crossfire of signal transduction cascades. Indian Journal of Biochemistry \& Biophysics. 2011;48(4):226-235. https://www.researchgate.net/publication/51770352.

21. Xu D, Ye D, Fisher M, JULIANO RL. Selective inhibition of P-glycoprotein expression in multidrug-resistant tumor cells by a designed transcriptional regulator. Journal of Pharmacology \& Experimental Therapeutics. 2002;302(3):963-971. https://doi.org/1124 /jpet.102.033639. 
22. Hauptman N, Glavac D. Long non-coding RNA in cancer. Int J Mol Sci. 2013;14 (3):4655-4669. https://doi.org/10.3390/ijms14034655.

23. Rinn JL, Kertesz M, Wang JK, Squazzo SL, Xu X, Brugmann SA, et al. Functional demarcation of active and silent chromatin domains in human HOX loci by noncoding RNAs. Cell. $2007 ; 129$ (7) :1311-1323. https://doi.org/1016/j.cell.2007.05.022.

24. Yan J, Dang YN, Liu SY, Zhang YF, Zhang GX. LncRNA HOTAIR promotes cisplatin resistance in gastric cancer by targeting miR-126 to activate the PI3K/AKT/MRP1 genes. Tumour Biol. 2016. https://doi.org/1007/s13277-016-5448-5.

25. Guo F, Cao ZL, Guo HQ, LI SQ. The action mechanism of IncRNA-HOTAIR on the drug resistance of non-small cell lung cancer by regulating Wnt signaling pathway. Exp Ther Med. 2018;15(6):4885-4889. https://doi.org/3892/etm.2018.6052.

26. Shao SL, Cui TT, Zhao W, Zhang WW, Xie ZL, Wang CH, et al. RNAi-based knockdown of multidrug resistance-associated protein 1 is sufficient to reverse multidrug resistance of human lung cells. Asian Pacific Journal of Cancer Prevention Apjcp. 2014;15(24):10597. http s://doi.org/7314/APJCP.2014.15.24.10597.

27. Xie ZL, Shao SL, Lv JW, Wang CH, Yuan CZ, Zhang WW, et al. Co-transfection and tandem transfection of HEK293A cells for overexpression and RNAi experiments. Cell Biology International. 2013;35(3):187-192. https://doi.org/1042/CBI20100470.

28. Shao SL, Zhang WW, Li XY, Zhang ZZ, Yun DZ, Fu B, et al. Reversal of MDR1 Gene-Dependent Multidrug Resistance in HL60/HT9 Cells Using Short Hairpin RNA Expression Vectors. Cancer Biotherapy \& Radiopharmaceuticals. 2010;25(2):171-177. https://doi.org/1089/cbr.2008. 0611.

29. Haase C, Lethaus B, Ruth Knüchel - Clarke, Hölzle F, Cassataro A, Braunschweig T. Development of a Rapid Analysis Method for Bone Resection Margins for Oral Squamous Cell Carcinoma by Immunoblotting. 2018;12: 210-20. https://doi.org/1007/s12105-017-0856-4

30. Loewen G, Jayawickramarajah J, Zhuo Y, Shan B. Functions of LncRNA HOTAIR in lung cancer. Journal of Hematology \& Oncology. 2014;7(1):90. https://doi.org/1186/s13045 -014-0090-4.

31. Baron V, Adamson ED, Calogero A, Ragona G, Mercola D. The transcription factor Egr1 is a direct regulator of multiple tumor suppressors including TGFbeta1, PTEN, p53, and fibronectin. Cancer Gene Therapy. 2006;13(2):115-124. https://doi.org/1038/sj.cgt.77008 96.

32. Guerquin MJ, Charvet B, Nourissat G, Havis E, Ronsin O, Bonnin MA, et al. Transcription factor Egr1 directs tendon differentiation and promotes tendon repair. Journal of Clinical Investigation. 2013;123(8):3564-3576. https://doi.org/1172/JCI67521.

33. Svaren J, Ehrig T, Abdulkadir SA, Ehrengruberi MU, Watson MA, Milbrandt J. Egr1 target genes in prostate carcinoma cells identified by microarray analysis. Journal of Biological Chemistry, 2000, 275(49):38524-31. https://doi.org/1074/jbc.M005220200.

34. Zhang HH, Chen XJ, Wang JK, Guang WH, Han W, Zhang H, et al. Egr1 decreases the malignancy of human non-small cell lung carcinoma by regulating KRT18 expression. Scientific Reports. 2014;4:5416. https://doi.org/1038/srep05416.

35. Virolle T, Krones-Herzig A, Baron V, Gregorio GD, Adamson ED, Mercola D. Egr1 Promotes Growth and Survival of Prostate Cancer Cells. Journal of Biological Chemistry. 2003;278(14):11802-10. https://doi.org/1074/jbc.M210279200.

36. Mikles DC, Schuchardt BJ, Bhat V, McDonald CB, Farooq A. Role of promoter DNA sequence variations on the binding of Egr1 transcription factor. Archives of Biochemistry \& Biophysics. 2014;549(3):1-11. https://doi.org/1016/j.abb.2014.03.005.

37. Guttman M, Rinn JL. Modular regulatory principles of large non-coding RNAs. Nature. 2012; 482:339-46. https://doi.org/1038/nature10887.

38. Mattick JS, Rinn JL. Discovery and annotation of long noncoding RNAs. Nature Structural \& Molecular Biology. 2015;22: 5-7. https://doi.org/1038/nsmb.2942.

39. Mattick JS. The genetic signatures of noncoding RNAs. PLoS Genet. 2009;5(4):e1000459. https://doi.org/1371/journal.pgen.1000459.

40. Rinn JL, Chang HY. Genome regulation by long noncoding RNAs. Annu Rev Biochem. 2012; 81:145-66. https://doi.org/1146/annurevbiochem-051410-092902.

41. Wilusz JE, Sunwoo H. Spector DL. Long noncoding RNAs: functional surprises from the RNA world. Genes Dev. 2009;23(13):1494-504. https://doi.org/1101/gad.1800909.

42. Xu YJ, Du Y, Fan Y. Long noncoding RNAs in lung cancer: what we know in 2015. Clin Transl Oncol. 2016;18:660-5. https://doi.org/1007/s12094-015-1448-y.

43. Schmitt AM, Chang HY. Long noncoding RNAs in Cancer pathways. Cancer Cell. 2016;29:452-63. https://doi.org/1016/j.ccell.2016.03.010.

44. Mercer TR, Dinger ME, Mattick JS. Long non-coding RNAs: insights into functions. Nature reviews Genetics. 2009;10:155-9. https://doi.org/1038/nrg2521.

45. Shi XF, Sun M, Liu HB, Yao YW, Song Y. Long non-coding RNAs: a new frontier in the study of human diseases. Cancer Lett. 2013;339:15966. https://doi.org/1016/j.canlet. 2013.06.013.

46. Quinn JJ, Chang HY. Unique features of long non-coding RNA biogenesis and function. Nature reviews Genetics. 2016;17:47-62. https://doi.org/1038/nrg.2015.10.

Page 9/19 
47. Bunch H. Gene regulation of mammalian long non-coding RNA. Mol Genet Genom. 2017;1:1-15. https://doi.org/1007/s00438-017-1370-9.

48. Han P, Chang CP. Long non-coding RNA and chromatin remodeling. RNA Biol. 2015; 12:1094-8. https://doi.org/1080/15476286.2015.1063770.

49. Salmena L, Poliseno L, Tay Y, Kats L, Pandolf PP. A ceRNA hypothesis: the Rosetta Stone of a hidden RNA language. Cell. 2011;146:353-8. https://doi.org/1016/j.cell.2011.07.014.

50. Tay Y, Rinn J, Pandolfi PP, The multilayered complexity of ceRNA crosstalk and competition. Nature. 2014;505:344-52. https://doi.org/1080/10.1038/nature12986.

51. Liu YT, Wang YQ, He XF, Zhang S, Wang K, Wu HJ, et al. LncRNA TINCR/miR-31-5p/C / EBP-alpha feedback loop modulates the adipogenic differentiation process in human adipose tissue-derived mesenchymal stem cells. Stem Cell Res. 2018;32:35-42. https://doi.org/10 16/j.scr.2018.08.016.

\section{Tables}

Table 1

Overexpression vector amplification primer sequence

\begin{tabular}{|ll|}
\hline Name & Sequence \\
\hline Egr1-F & CCCAAGCTTATGGCCGCGGCCAAG \\
\hline Egr1-R & CCGGAATTCTTAGCAAATTTCAATTG \\
\hline miR-6807-F & CGCGGATCCGAAGTTGTCACCTCCCTAC \\
miR-6807-R & CCGGAATTCTCCACCAGCACAGCAG \\
\hline
\end{tabular}

Table 2

shRNA sequence

\begin{tabular}{|c|c|}
\hline Name & Sequence \\
\hline shEgr1-1-F & GATCCGACAACTACCCTAAGCTGGAGGAGATCGAAATCTCCTCCAGCTTAGGGTAGTTGTCTTTTTTGAATTCA \\
\hline shEgr1-1-R & AGCTTGAATTCAAAAAAGACAACTACCCTAAGCTGGAGGAGATTTCGATCTCCTCCAGCTTAGGGTAGTTGTCG \\
\hline shEgr1-2-F & GATCCGACGACAGCAGTCCCATTTACTCGAAAGTAAATGGGACTGCTGTCGTCTTTTTTGAATTCA \\
\hline shEgr1-2-R & AGCTTGAATTCAAAAAAGACGACAGCAGTCCCATTTACTTTCGAGTAAATGGGACTGCTGTCGTCG \\
\hline shEgr1-3-F & GATCCGCGATGAACGCAAGAGGCATACGAATATGCCTCTTGCGTTCATCGCTTTTTTGAATTCA \\
\hline shEgr1-3-R & AGCTTGAATTCAAAAAAGCGATGAACGCAAGAGGCATATTCGTATGCCTCTTGCGTTCATCGCG \\
\hline shEgr1-4-F & GATCCGCTTTCGGACATGACAGCAACCGAAGTTGCTGTCATGTCCGAAAGCTTTTTTGAATTCA \\
\hline shEgr1-4-R & AGCTTGAATTCAAAAAAGCTTTCGGACATGACAGCAACTTCGGTTGCTGTCATGTCCGAAAGCG \\
\hline shLncRNA HOTAIR-1-F & GATCCGAAGGTGAAAGCGAACCACGCACGAATGCGTGGTTCGCTTTCACCTTCTTTTTTGAATTCA \\
\hline shLncRNA HOTAIR-1-R & AGCTTGAATTCAAAAAAGAAGGTGAAAGCGAACCACGCATTCGTGCGTGGTTCGCTTTCACCTTCG \\
\hline shLncRNA HOTAIR-2-F & GATCCGAATTGATTCCTTTGGACTGTACGAATACAGTCCAAAGGAATCAATTCTTTTTTGAATTCA \\
\hline shLncRNA HOTAIR-2-R & AGCTTGAATTCAAAAAAGAATTGATTCCTTTGGACTGTATTCGTACAGTCCAAAGGAATCAATTCG \\
\hline shLncRNA HOTAIR-3-F & GATCCGAACTTCCTCCTGCTATTAAGACGAATCTTAATAGCAGGAGGAAGTTCTTTTTTGAATTCA \\
\hline shLncRNA HOTAIR-3-R & AGCTTGAATTCAAAAAAGAACTTCCTCCTGCTATTAAGATTCGTCTTAATAGCAGGAGGAAGTTCG \\
\hline
\end{tabular}

Table. 3 Dual luciferase amplification primer 
NameSequence

pGL3-F1『gtgccagaacatttctctatcgataGGTACCCTGAACCTCAGTTTCCCCA

$600-\mathrm{f} \otimes$

$\triangle$ E1 ggaaCCCGGGGCGCCGAGAGGTGGCTGGTCCGGCTGCCCACGCCGAGACGCGCGCCGCATCCCCGTGACGCGCGGGCCAACCAGGCGGCGTTG r囚GGAACGCTAGCGCTGGCGGCGGCGGCGGCGGCGGCGCAGGGAGCCGGGGCCGGGGCCGCAACGCCGCCTGGTTGGCC R1囚CGGACCAGCCACCTCTCGGCGCCCCGGGCCTGGACCCCGCGCCACCCCCA

pGL3-F1『gtgccagaacatttctctatcgataGGTACCCTGAACCTCAGTTTCCCCA

600- f囚ggaaCCCGGGGCGCCGAGAGGTGGCTGGTCCGGCTGCCCACGCCGAGACGCGCGCGGGGCGGGGCGGGGTGGGGCGGGGCC

$\triangle$ E2 GCCGCATCCCCGTGACGCGCGGGCCAACCAGGCGGCGTTG r冈GGAACGCTAGCGCTGGCGGCGGCGGCGGCGGCGGCGCAGGGAGCCGGGGCCGGGGCCGCAACGCCGCCTGGTTGGCC R1囚CGGACCAGCCACCTCTCGGCGCCCCGGGCCTGGACCCCGCGCCACCCCCA

pGL3-F1『gtgccagaacatttctctatcgataGGTACCCTGAACCTCAGTTTCCCCA

600- f囚ggaaCCCGGGGCGCCGAGAGGTGGCTGGTCCGGCTGCCCACGCCGAGACGCGCGAGGTGAGCGGGCGCCGGTGGGGCGGG

$\triangle$ E3 GCCGCCGCATCCCCGTGACGCGCGGGCCAACCAGGCGGCGTTG r囚GGAACGCTAGCGCTGGCGGCGGCGGCGGCGGCGGCGCAGGGAGCCGGGGCCGGGGCCGCAACGCCGCCTGGTTGGCC R1』CGGACCAGCCACCTCTCGGCGCCCCGGGCCTGGACCCCGCGCCACCCCCA

\section{Table 4}

Real-time RT-PCR primers

\begin{tabular}{|l|l|}
\hline Name & Sequence \\
\hline Egr1-F & TGACCCGTTCGGATCCTTTC \\
\hline Egr1-R & GAGTGGTTTGGCTGGGGTAA \\
\hline MRP1-F & GCCTGTTTTGGTAAAGAACTGGAAG \\
\hline MRP1-R & CCTTGGAACTCTCTTTCGGCTG \\
\hline miR-6807-3p-F & ACACTCCAGCTGGGCACTGCATTCCTGCTTG \\
\hline miR-6807-3p-R & CTCAACTGGTGTCGTGGA \\
\hline LncRNA HOTAIR-F AAATATGGCGGCGTCTACACGGA \\
\hline LncRNA HOTAIR-RTCCAGAACCCTCTGACATTTGCCT \\
\hline B-actin-F & AGCGAGCATCCCCCAAAGTT \\
\hline B-actin-R & GGGCACGAAGGCTCATCATT \\
\hline U6-F & CTCGCTTCGGCAGCACA \\
\hline U6-R & AACGCTTCACGAATTTGCGT \\
\hline
\end{tabular}

Table 5

$\mathrm{IC}_{50}$ value in A549/DDP cells

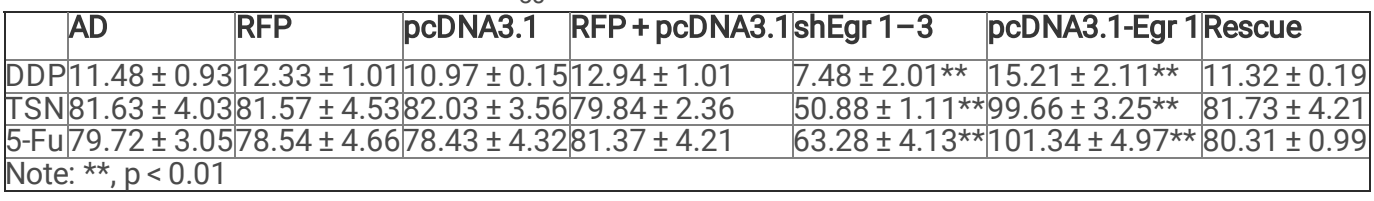

\section{Figures}


A
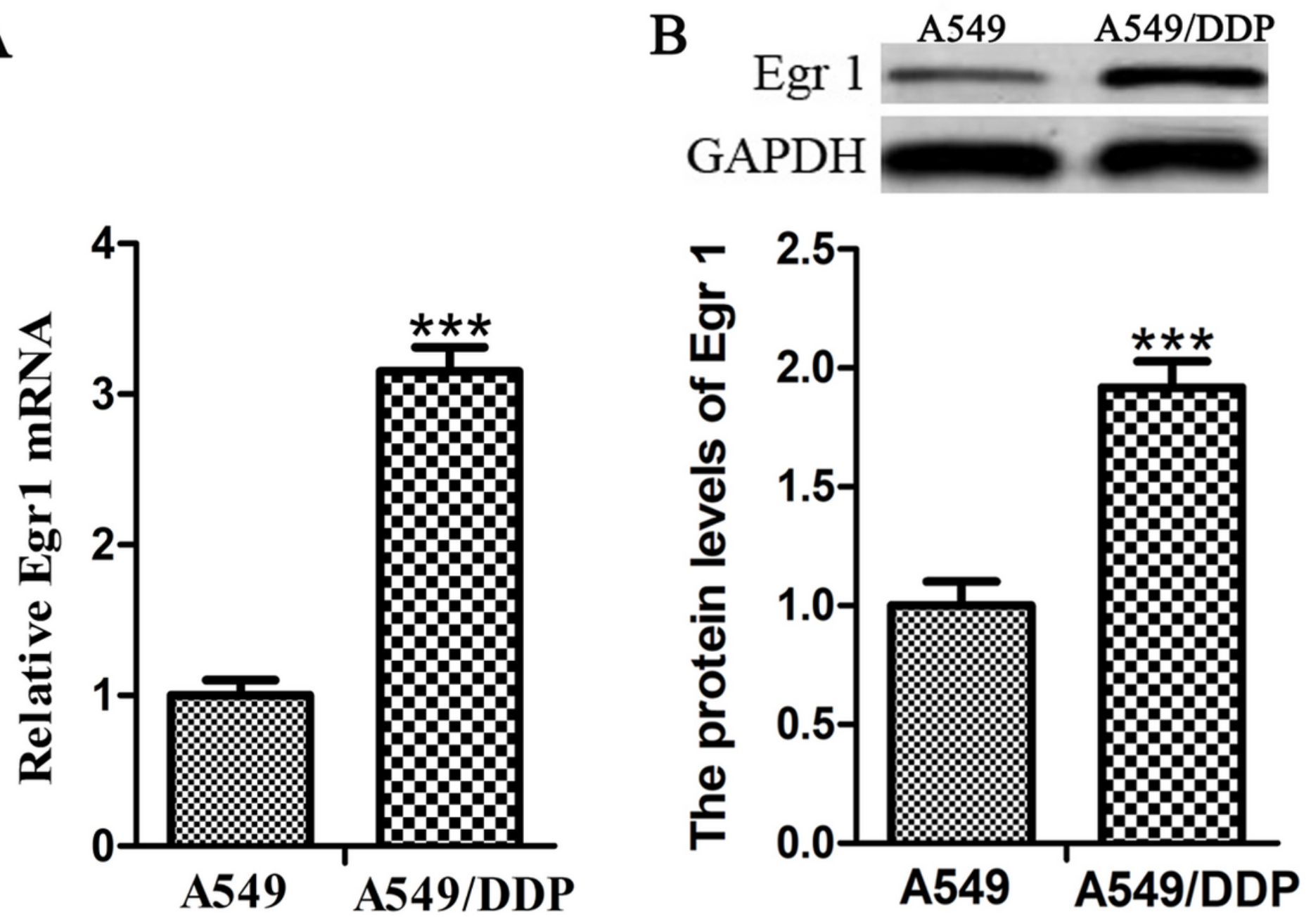

Figure 1

Expression of EGR1 mRNA and protein in A549 cells and A549/DDP (AD) cells. (A) Differential expression of EGR1 mRNA in A549 and A549/DDP cells, normalized to $\beta$-actin. $(n=3)$. (B) Differential expression of EGR1 and GAPDH proteins in A549 and A549/DDP cells. *** ( $<$ < 0.001). 


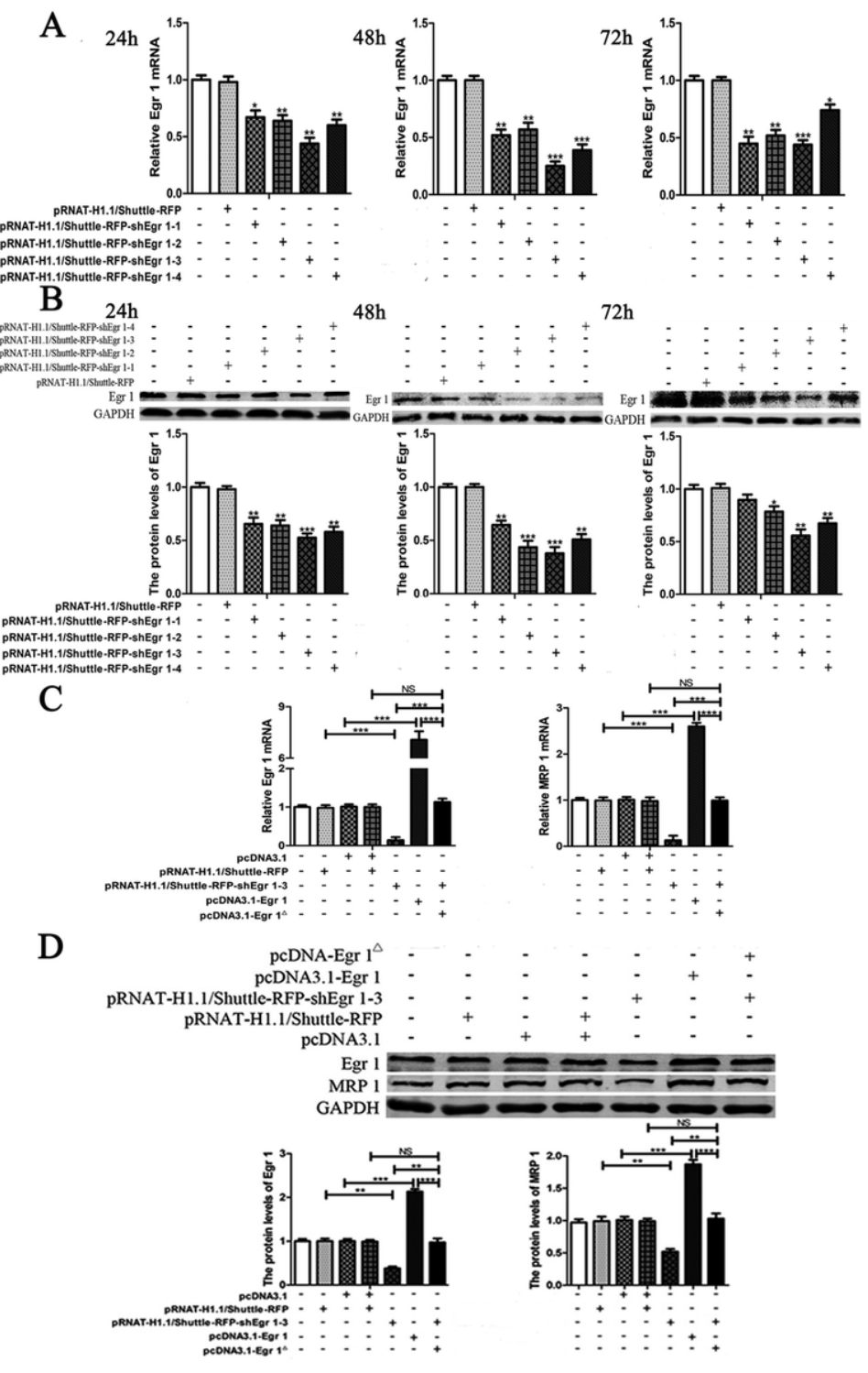

Figure 2

EGR1 upregulates expression of MRP1. (A) Relative expression of EGR1 mRNA after 24, 48, and 72 hours of transfection. Values are expressed as relative to that of the internal control, $\beta$-actin. Expression in A549/DDP transfected with empty vector (Ctrl) was set to $1 ; n=3$. (B) Relative expression of EGR1 protein after 24,48 , and 72 hours of transfection. * $(p<0.05),{ }^{\star *}(p<0.01),{ }^{\star \star \star}(p<0.001)$. (C) A549/DDP were transfected with different expression vectors. Levels of EGR1 and MRP1 mRNAs are expressed as relative to that of the internal control, $\beta$-actin. Expression in A549/DDP transfected with empty vector (Ctrl) was set to $1 ; n=3$. (D) A549/DDP were transfected with different expression vectors; shown are the protein expression levels of EGR1 and MRP 1; $(p<0.05), * \star(p<0.01), * \star *(p<0.001)$. NS, no statistically significant difference. 

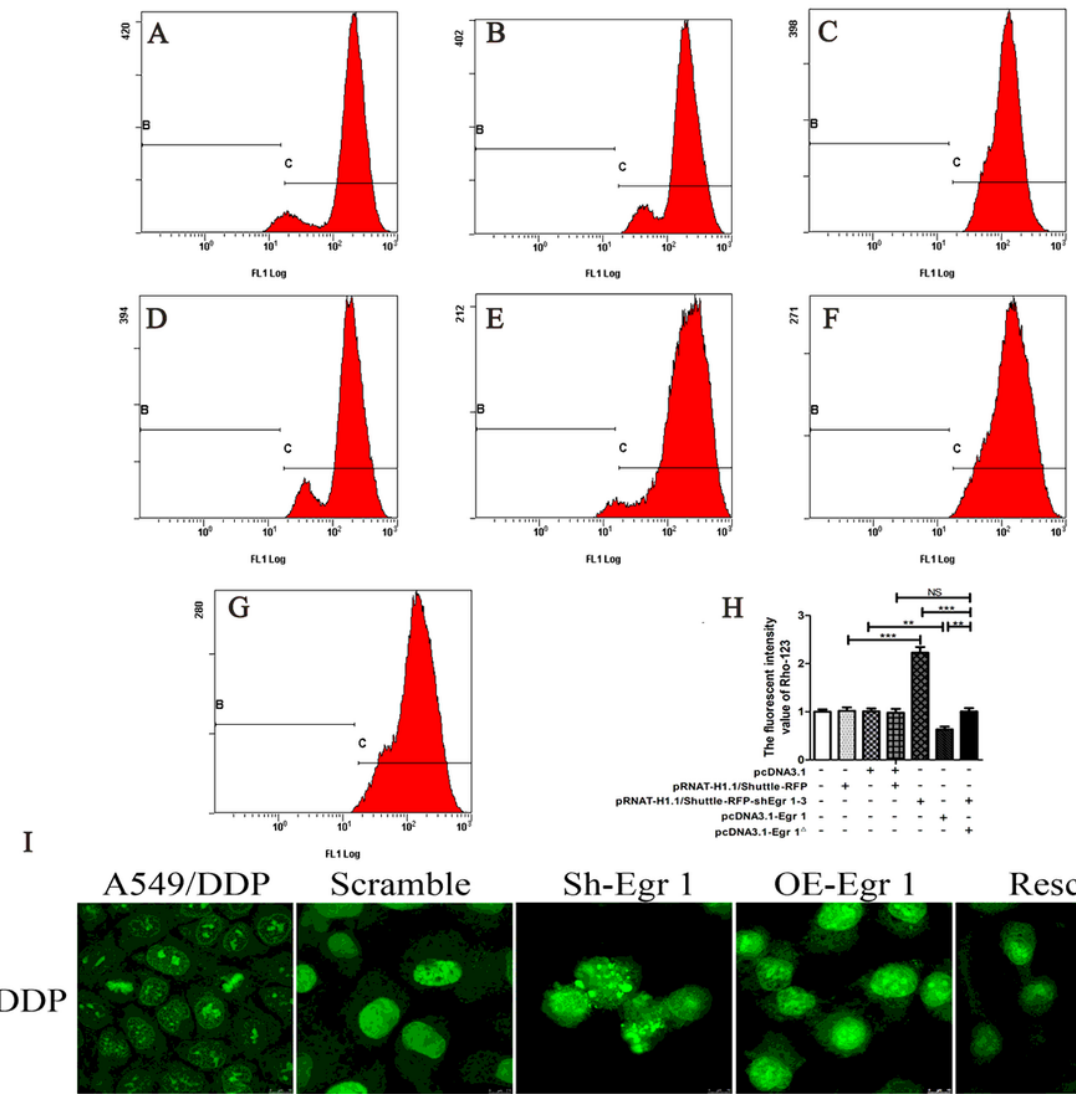

Scramble

Sh-Egr 1

OE-Egr 1

Rescue

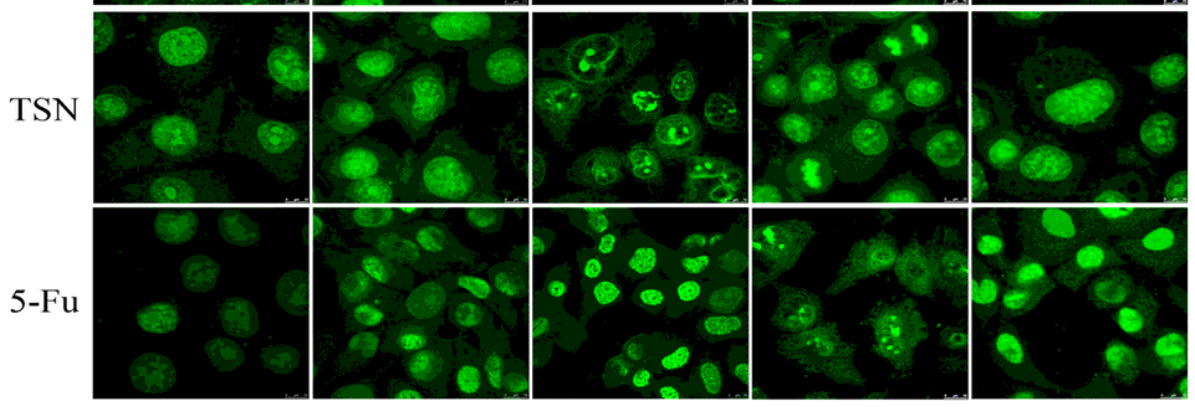

\section{Figure 3}

EGR1 knockdown reduces MDR and promotes apoptosis in A549/DDP cells. (A-H) Fluorescence intensity of Rho-123 in A549/DDP cells transfected with different vectors, analyzed by flow cytometry. (I) Cell morphology observed with laser confocal microscopy. * $(p<0.05)$, ** $(p<$ $0.01), * \star *(p<0.001)$; NS, no statistically significant difference. 


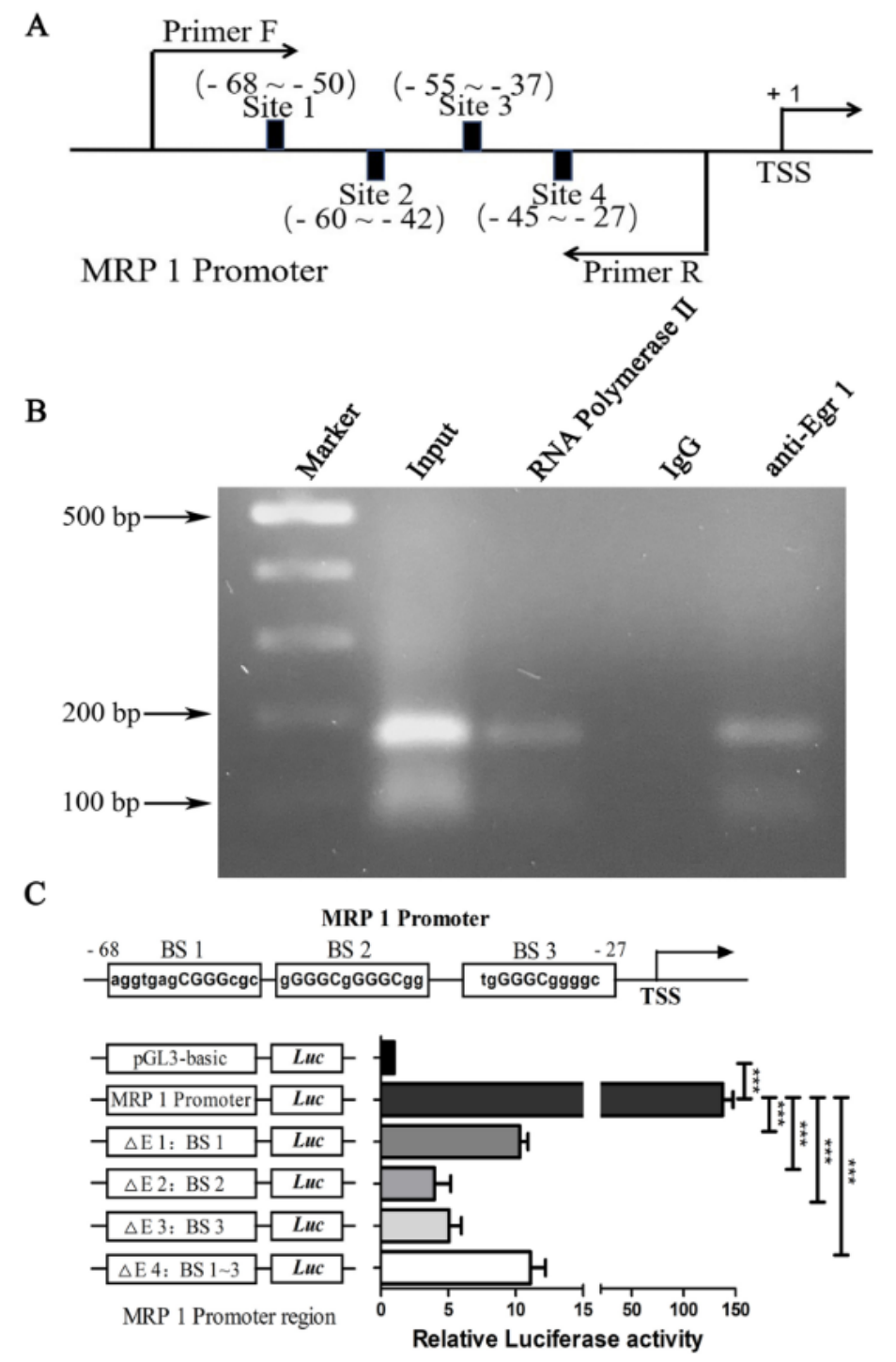

\section{Figure 4}

EGR1 activates MRP1 expression through binding to the MRP1 promoter. (A) A schematic representation of the human MRP1 gene promoter and the four putative EGR1 binding sites. (B) ChIP assay was used to detect the direct binding of EGR1 to the MRP1 promoter. Lysates from

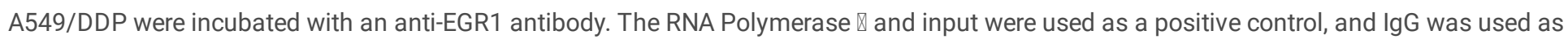
a negative control. (C) HEK-293T cells were co-transfected with pcDNA3.1-EGR1 and pGL3-600- $\triangle E 1$, pGL3-600- $\triangle E 2$, pGL3-600- $\triangle E 3$, or pGL3600- $\triangle \mathrm{E} 4$ reporter, and the relative luciferase activity was determined. The luciferase activity of mock pcDNA3.1-basic-transfected group was designated as 1.00 . The results are the means \pm S.D. of three experiments performed in duplicate. $* \star \star ~(p<0.001)$. The left side is a schematic representation of the reporter gene constructs. The bar graphs on the right side represent the relative levels of luciferase activity in each of the transfected samples. 
A
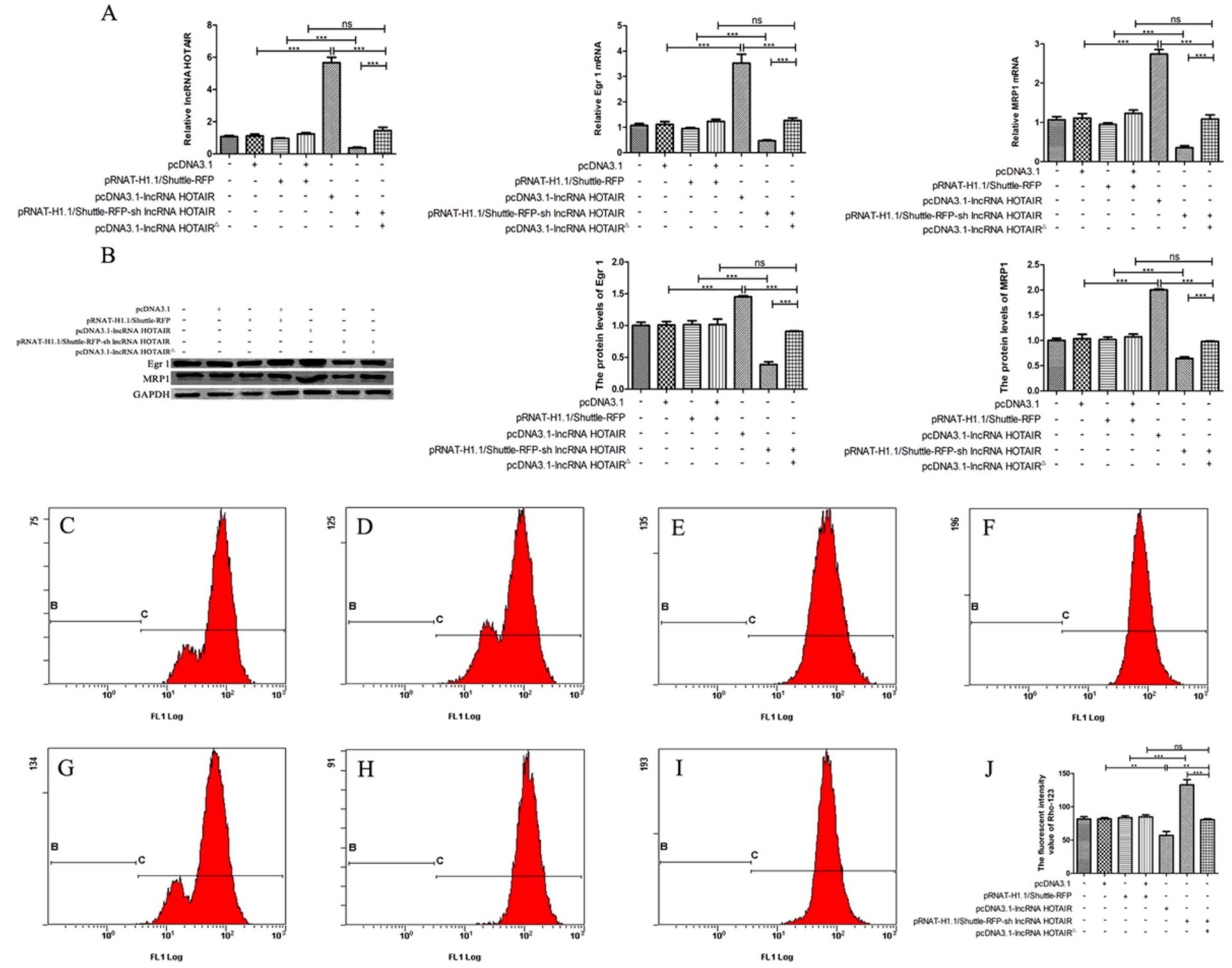

Figure 5

LncRNA HOTAIR regulates EGR1 and MRP1 gene expression and MDR. (A) Relative expression of HOTAIR, EGR1, and MRP1 mRNA after 48 hours of transfection. Values are expressed as relative to the value of the internal control $\beta$-actin. The relative expression in A549/DDP transfected with empty vector (Ctrl) was set to $1 ; n=3$. (B) Relative expression of EGR1 and MRP1 proteins 48 hours after transfection. (C) Flow cytometry was used to detect the change of fluorescence intensity of Rho-123 in A549/DDP cells after transfection with different expression vectors. ${ }^{*}(p<0.05),{ }^{\star *}(p<0.01),{ }^{\star \star \star}(p<0.001) ; N S$, no statistically significant difference. 
A
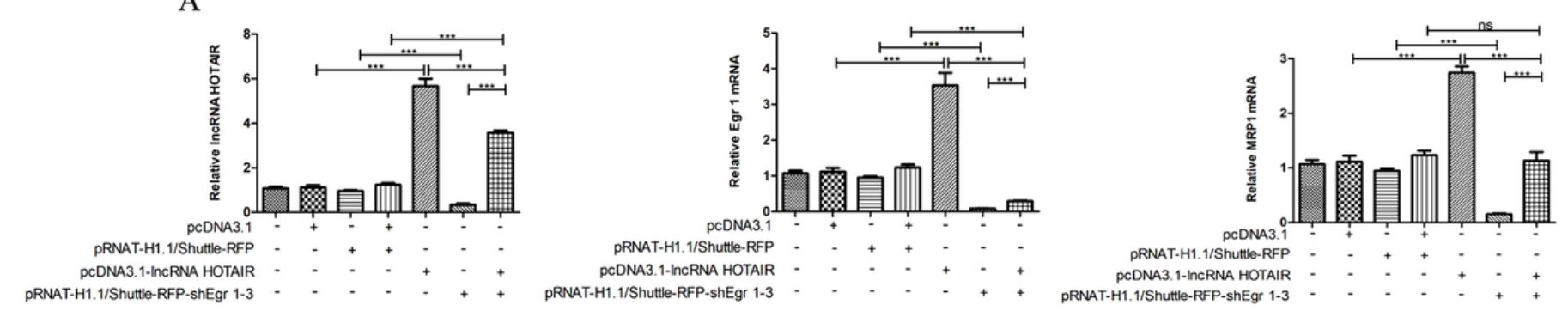

B
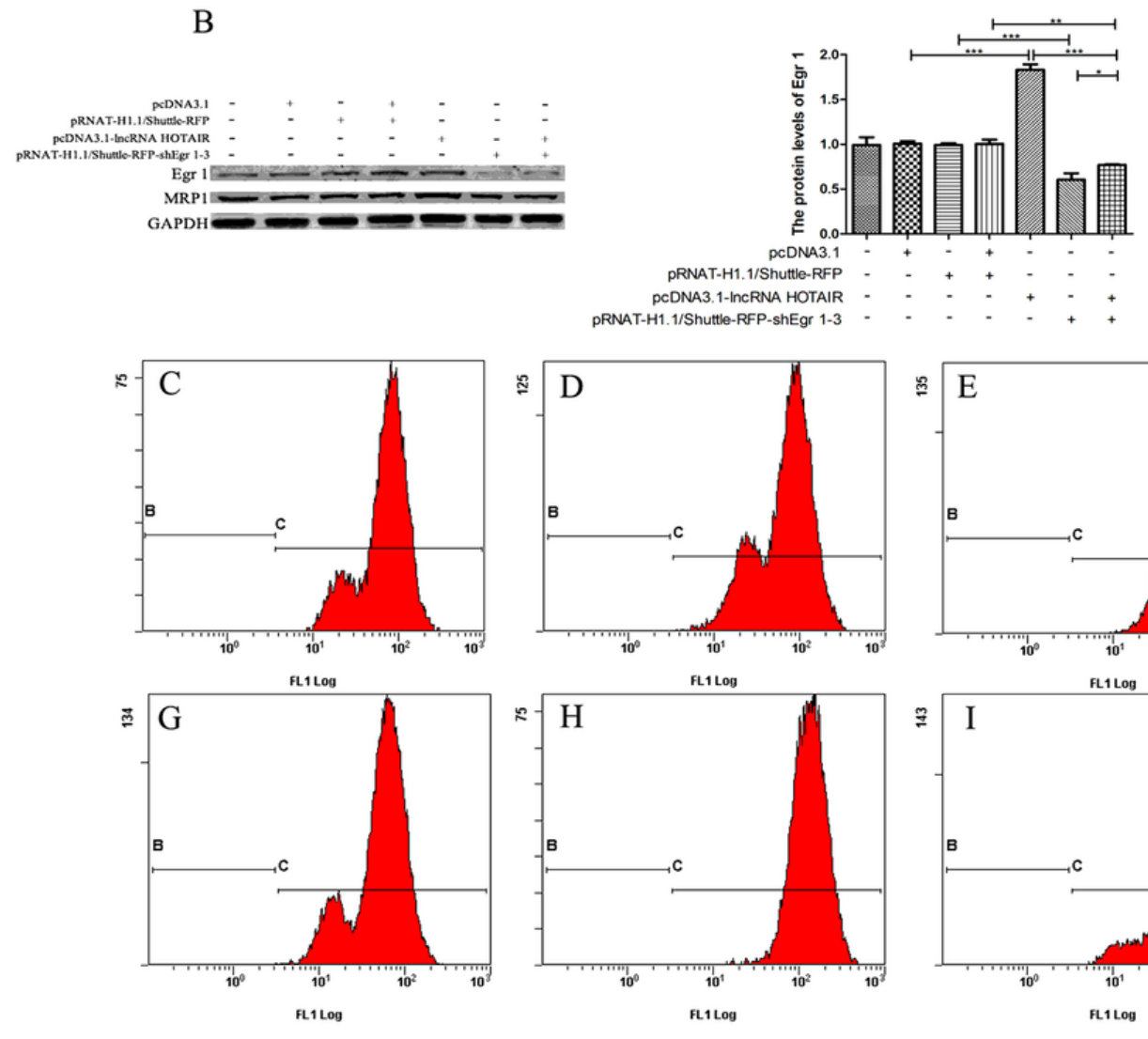
PRNAT-H1.1/Shuttle-RFP-shEgr 1-3
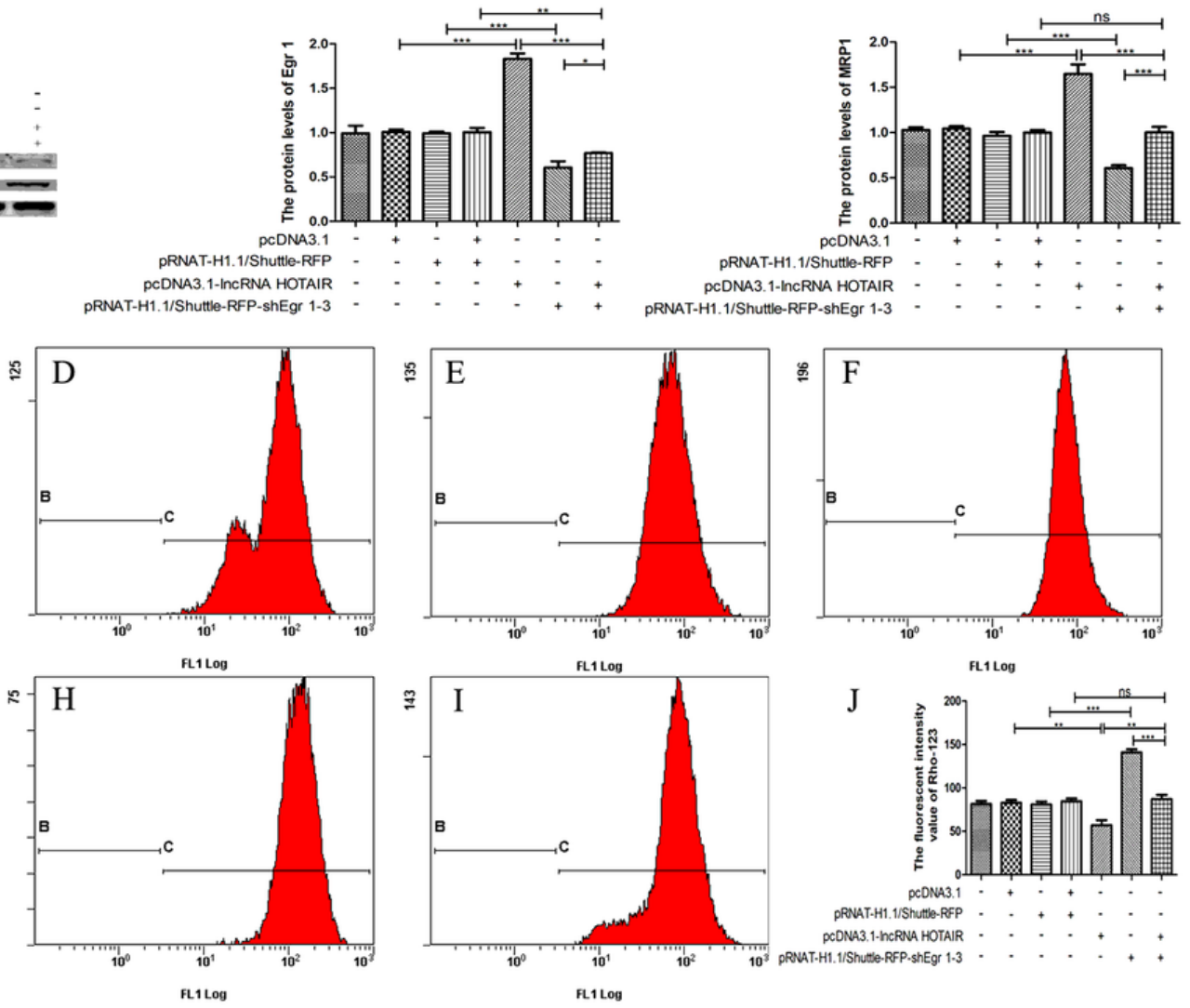

Figure 6

EGR1 is critical for HOTAIR-mediated MRP1 upregulation and MDR. (A) Relative expression of HOTAIR, EGR1, and MRP1 mRNA after 48 hours of transfection. Values are expressed as relative to the value of the internal control $\beta$-actin. The relative expression in A549/DDP transfected with empty vector (Ctrl) was set to $1 ; n=3$. (B) Relative expression of EGR1 and MRP1 proteins 48 hours after transfection. (C) Flow cytometry was used to detect the change of fluorescence intensity of Rho-123 in A549/DDP cells after transfection with different expression vectors. * $(p$ $<0.05)$, ** $(p<0.01)$, *** $(p<0.001)$; NS, no statistically significant difference. 
A

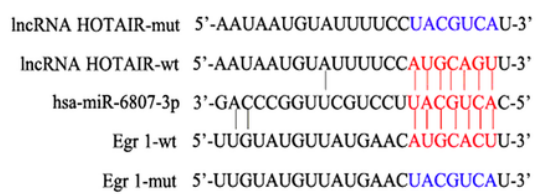

B
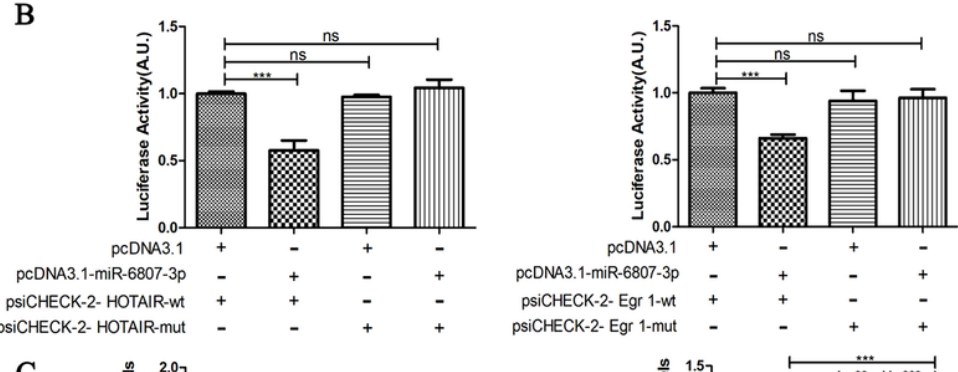

C

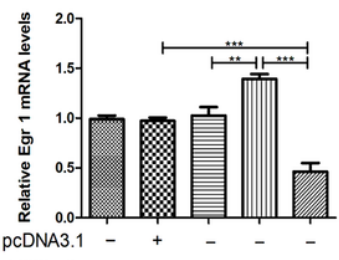

pCDNA3.1-miR-6807-3p - $\quad-\quad-\quad+$

miR-6807-3p-NC - -+-

miR-6807-3p-1 -

D

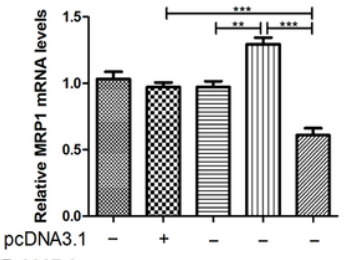

pcDNA3.1-miR-6807-3p - $\quad-\quad-\quad+$
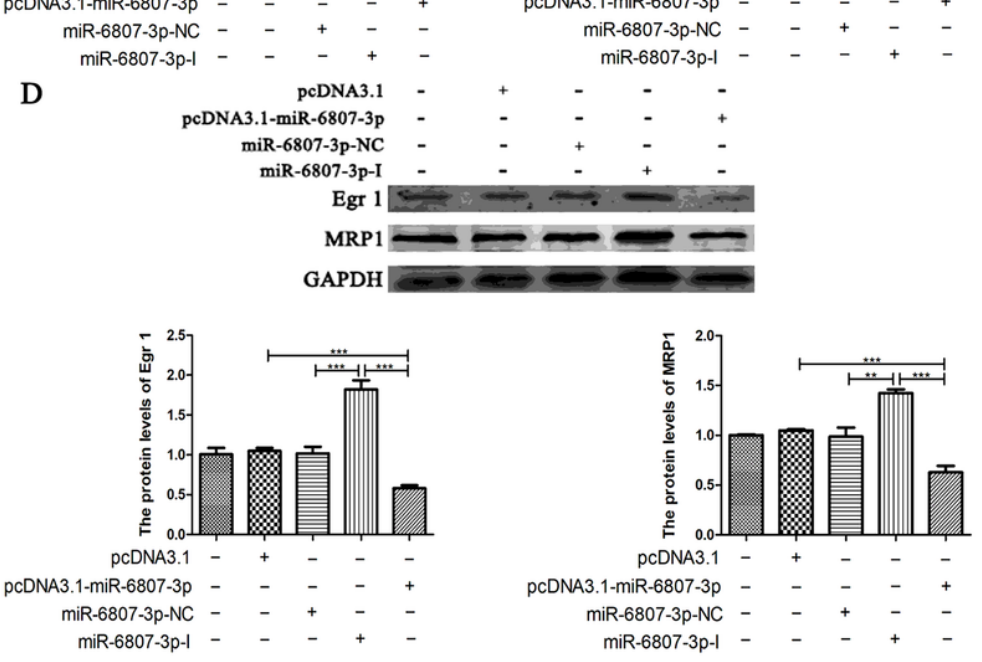

Figure 7

HOTAIR regulates the expression of Egr1 by sponging miR-6807-3p. (A) Bioinformatic analysis predicting the targets of miR-6807-3p. (B) Dual luciferase confirms that miR-6807-3p targets IncRNA HOTAIR and EGR1 3' UTR. (C) Effect of miR-6807-3p on EGR1 and MRP1 mRNA. (D)

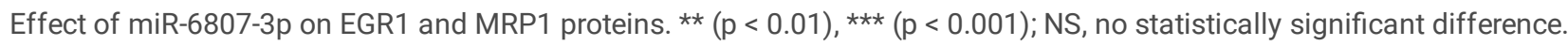




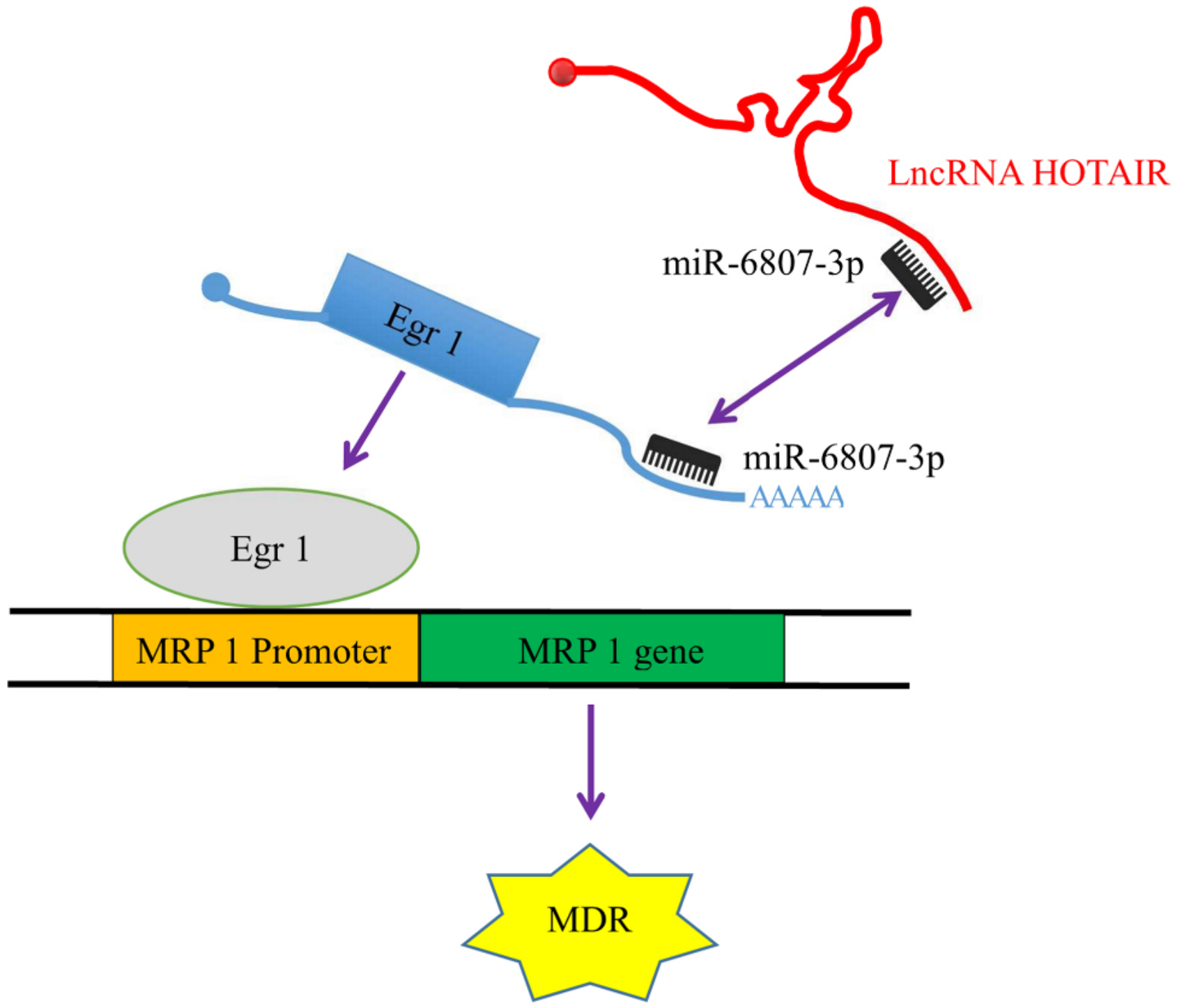

Figure 8

Effect of EGR1-mediated IncRNA HOTAIR on MRP1 gene expression and MDR in lung cancer.

\section{Supplementary Files}

This is a list of supplementary files associated with this preprint. Click to download.

\section{- FigS1.docx}

- fig.S1.tif 